\title{
Abnormal Tsunamis Caused by the June 13, 1984, Torishima, Japan, Earthquake
}

\author{
KENII SATAKE ${ }^{1}$ AND HIROO KANAMORI
}

\author{
Seismological Laboratory, California Institute of Technology, Pasadena
}

\begin{abstract}
An earthquake with an $M S=5.6\left(m_{b}=5.5\right)$ which occurred near Torishima, Japan, on June 13,1984 , generated abnormally large tsunamis (tsunami magnitude $M_{t}=7.3$ ) for its relatively small earthquake magnitude. The maximum amplitude of the tsunamis is not a simple function of distance as the magnitude formula implies. In order to quantify the abnormal tsunamis, we modeled the tsunami source using a finite difference computation on the actual bathymetry. The source of these abnormal tsunamis is modeled as a water surface displacement, with a radius of $12 \mathrm{~km}$ and maximum water height of $13 \mathrm{~cm}$. The displaced water volume is $4 \times 10^{13} \mathrm{~cm}^{3}$, and the potential energy is calculated as $2 \times 10^{17} \mathrm{ergs}$. If this water displacement is due to a fault motion at $5 \mathrm{~km}$ depth, a moment magnitude $M_{w}$ is estimated to be 6.3. This value is larger than $M_{w}$ estimated from seismic waves by 0.7 , but smaller than $M_{t}$ by 1.0 . The former difference suggests that the earthquake source is very different from an ordinary faulting. If we assume the source is a horizontally lying tensile crack at shallow depth (about $2 \mathrm{~km}$ ), that explains both the water surface displacement and the seismic moment tensor. The tensile crack is interpreted as an injection of material, as suggested by a seismological study. The discrepancy between $M_{w}$ and $M_{t}$ indicates that the propagation path is responsible for the observed large tsunamis. The numerical computation shows a focusing of energy during the propagation of the tsunami along the shallow Izu-Bonin ridge system. Thus the abnormally large tsunamis from the Torishima earthquake are a result of both source and path effects.
\end{abstract}

\section{INTRODUCTION}

Abnormal tsunamis were observed on the southern coast of Honshu and the Izu Islands associated with an $M S=5.6$ $\left(m_{b}=5.5\right)$ earthquake near Torishima, Japan, on June 13, 1984 [Okada, 1984; Hatori, 1985]. The hypocentral parameters given by ISC (International Seismological Centre) are: origin time $0229: 23 \mathrm{UT}, 31.49^{\circ} \mathrm{N}, 140.08^{\circ} \mathrm{E}$ and depth 11 $\mathrm{km}$. This event was located on a ridge system on the back arc side of the Japan Trench (Figure 1).

At Yaene on Hachijo-jima (Hachijo Island, Figure 1), 190 $\mathrm{km}$ north of the epicenter, tsunamis were visually observed with a peak-to-peak amplitude of 130 to $150 \mathrm{~cm}$. This is abnormally large for a tsunami from an earthquake with magnitude 5.6. The tsunami magnitude $M_{t}[A b e, 1979]$ of this earthquake determined from the observed tsunami amplitudes is 7.3 [Abe, 1988], about two units larger than the seismic magnitudes. The tsunami magnitude scale is calibrated against the seismic magnitude scale such that both have about the same value for ordinary seismic events. Because of this discrepancy, Abe [1988] categorized this event as a tsunami earthquake. Tsunami earthquakes are events for which the tsunamis are abnormally large compared with the seismic wave radiation [Kanamori, 1972].

Seismic waves from this event have been analyzed by several investigators. Dziewonski et al. [1985] applied a centroid moment tensor inversion method to the seismic data

\footnotetext{
${ }^{1}$ now at Department of Geological Sciences, University of Michigan, Ann Arbor.
}

\section{Copyright 1991 by the American Geophysical Union.}

and obtained a scalar seismic moment of $3.4 \times 10^{24} \mathrm{dyn} \mathrm{cm}$, which corresponds to a moment magnitude $M_{w}$ of 5.6. Their solution has a significant amount of non-double-couple component. Kanamori et al. [1986] analyzed long-period surface waves and found that this event cannot be explained by an ordinary double couple; it is best explained by a compensated linear vector dipole (CLVD). They interpreted the CLVD source as a combination of an implosive source at depth and a sudden injection of water-magma mixture into shallow sediments.

In this paper, we analyze the tsunami data to examine the cause of abnormal tsunamis. Since the tsunami source is a water surface displacement, we first estimate the displaced water volume at the source using numerical computations. The propagation effect is included in the numerical computations on actual bathymetric data; hence comparison of the observed and computed tsunami waveforms yields direct information on the tsunami source. The numerical computations have been applied to tsunamis from large earthquakes at relatively short distances [Aida, 1978; Satake, 1989]. The tsunami source of the Torishima event, however, is far from the coastal region, and the propagation effect is expected to be very different. We will show that, although the anomalous tsunami amplitude is partly due to the propagation effect on the ridge system, the source of the Torishima earthquake is anomalously efficient in exciting isunamis, suggesting a mechanism very different from that for ordinary seismic events.

\section{OBSERVED TSUNAMIS AND NUMERICAL COMPUTATIONS}

For the tsunamis from the Torishima event, not only the average amplitude but also the geographical distribution of amplitude is anomalous. Figure 2 shows the maximum (peak- 


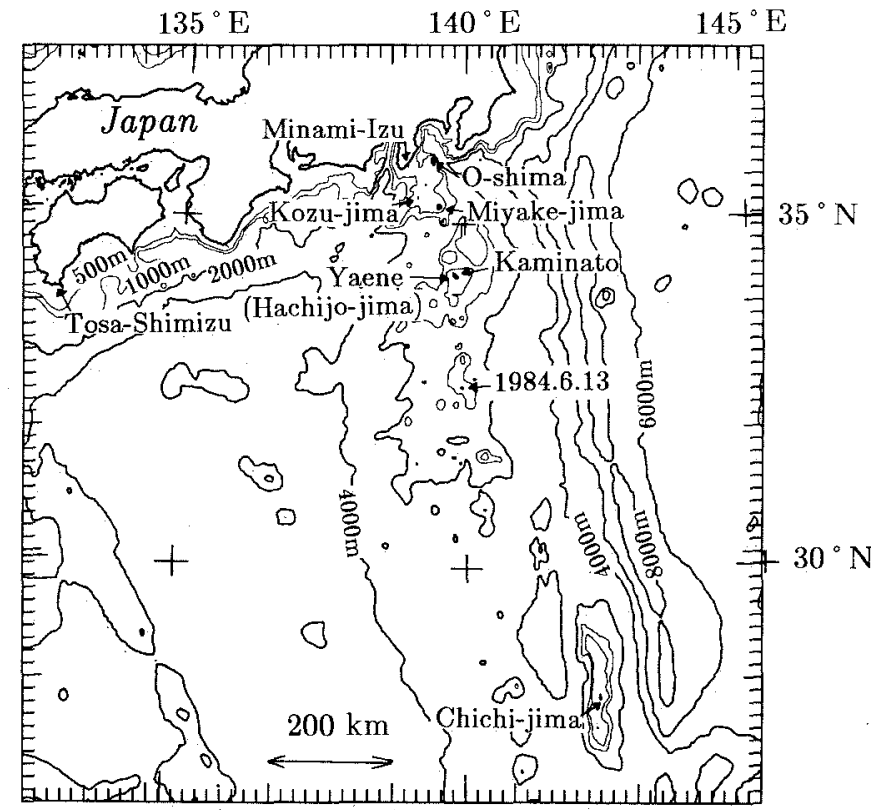

Fig. 1. The bathymetry of the computational area. Each tick mark indicates 10 grid spacings. The epicenter and tide gauge stations are also shown. Finer grid systems are employed near the tide gauge stations.

to-peak) amplitude of tsunamis recorded on tide gauges as a function of distance from the source. Analytical calculations of tsunamis on a uniform-depth ocean indicate that the tsunami amplitude decays with the travel distance [e.g., Takahashi, 1942; Kajiura, 1963; Ward, 1980; Comer, 1984; Okal, 1988]. The formula for the tsunami magnitude scale includes this distance dependence [Abe, 1979; Comer, 1980]. Abe [1988] assigned the tsunami magnitude $M_{t}=7.3$ to the Torishima earthquake. The predicted tsunami amplitude from an $M_{t}=7.3$ source is also shown as a dotted line in Figure 2 . As seen in the figure, the trend of the observed amplitudes

\section{Torishima Tsunami}

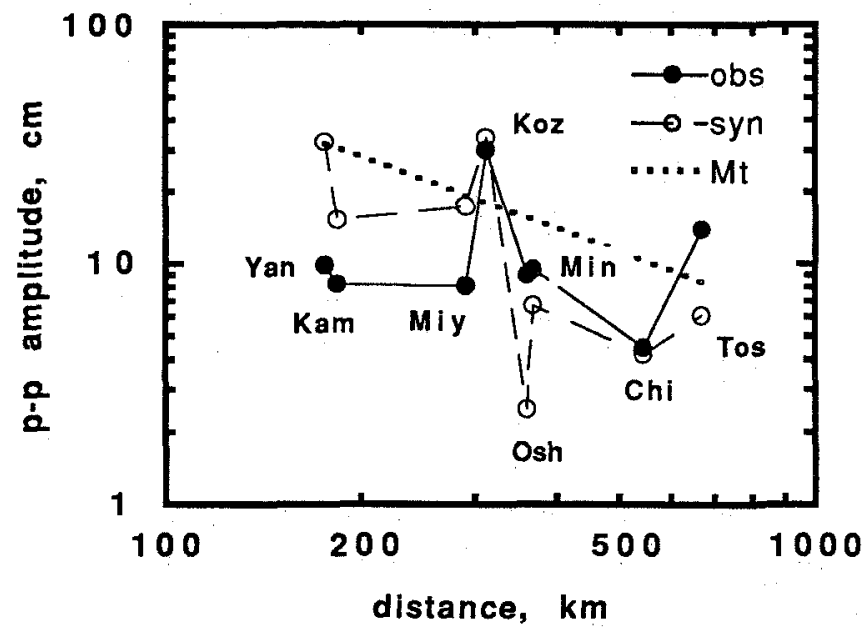

Fig. 2. Tsunami amplitudes as a function of propagation distance. Solid circles show the observed peak-to-peak amplitudes. Open circles are computed amplitudes from the source model obtained in this study. The dotted line indicates the predicted amplitudes from the tsunami magnitude scale for an $M_{t}=7.3$ event: deviates significantly from the predicted line. First, the overall slope is smaller than the predicted one. Next, at a few stations, namely, Kozu-jima and Tosa-Shimizu, the amplitudes are anomalously large. These indicate that the assumption of uniform-depth ocean is invalid and that numerical computations on actual bathymetry are necessary to quantify the tsunami source from the observed waveforms.

Numerical computations, namely, finite difference computations, have been used to compute tsunami waveforms and to determine the tsunami source properties [Aida, 1978; Ando, 1982; Satake, 1989]. The details of the computational method are described in these papers and not repeated here. The computational area is shown in Figure 1 with its bathymetry. Grid spacing for the finite difference computation is $2 \mathrm{~km}$ in the open sea, and the number of grid points is $600 \times 600$. Variable grid spacings, with $250 \mathrm{~m}$ being the smallest, are used near tide gauge stations to incorporate the nearshore effects. The wave fields are computed with a time step of $3 \mathrm{~s}$ to satisfy the stability condition of the finite difference computation.

Satake [1989] inverted tsunami waveforms from large earthquakes to determine the slip distribution on the fault plane. The tsunamis from the Torishima earthquake $\left(M_{t}=7.3\right)$ have much smaller signal-to-noise ratio compared with tsunamis from such great earthquakes $\left(M_{t}>8\right)$ observed at shorter distances. Further, because of the unusually large discrepancy between tsunami and seismic magnitudes, we assume a more general source than ordinary faulting. The tsunami source may be best modeled by a simple water displacement, a circular source with an elliptic uplift profile parameterized by the radius $R$ and the maximum height $H$ (Figure 3). Because of the low signal-to-noise ratio and our incomplete knowledge about the bathymetry, especially near the coastal area, we do not expect to be able to explain the waveforms in detail. Our aim here is to explain the overall amplitude and the gross features of the observed tsunamis. Since the basic equations of the numerical computation are linear, the amplitude of computed waveforms for a given $R$ is proportional to the source height $H$. Hence if we can determine the radius $R$, we can estimate $H$ by matching the observed amplitude with synthetics. The determination of $R$ is, however, more difficult. We will first estimate $R$ by comparing the waveform features and then estimate $H$ from amplitude comparisons.

\section{Tsunami Source Model}

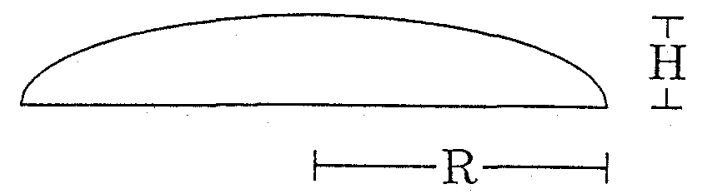

$$
\begin{aligned}
& \mathrm{R}=12 \mathrm{~km} \\
& \mathrm{H}=13 \mathrm{~cm} \\
& \mathrm{~V}=4 \times 10^{13} \mathrm{~cm}^{3} \\
& \mathrm{E}_{\mathrm{t}}=2 \times 10^{17} \mathrm{erg}
\end{aligned}
$$

Fig. 3. The tsunami source model used. 
The center of the source is located near Daini-Sumisu Knoll, where the water depth is as shallow as $300 \mathrm{~m}$. We assumed that the uplift was completed in $30 \mathrm{~s}$, which is comparable to the duration of the source estimated by seismic wave analysis [Kanamori et al,, 1986]. However, the tsunami waves are insensitive to the source process time, since the tsunami velocity in $300-\mathrm{m}$-deep water is as slow as 0.05 $\mathrm{km} / \mathrm{s}$. In other words, it is impossible to resolve the source time function from tsunami records. The modeled source has a symmetric radiation of tsunami waveforms at all azimuths The directivity of tsunamis, which has been reported from a few great earthquakes, is not considered here, since the directivity may not be very large from tsunamis of this size and the azimuthal coverage of stations is not good enough to resolve the directivity even if it exists.

\section{MOdeling THE TSUNAMI SOURCE}

We computed tsunami waveforms at the eight tide gauge stations shown in Figure 1 for three different source radii. Figure 4 shows the observed and synthetic waveforms computed from sources with $R=6,12$, and $18 \mathrm{~km}$. The first part (about $15 \mathrm{~min}$ from the onset, bracketed by dash-dot lines in Figure 4) of the waveforms represents the direct wave from the source, and the period of the first cycle is primarily determined by the source dimension. As $R$ increases from 6 to $18 \mathrm{~km}$, the period of the first cycle increases from about 4 to about $12 \mathrm{~min}$. Comparing the period of the synthetics with that observed, we conclude that $R$ is about $12 \mathrm{~km}$.

Other useful information can be obtained from the reverberation in the later part. This is most clearly seen at Kozujima. The synthetics for $R=6$ and $12 \mathrm{~km}$ exhibit largeamplitude reverberations, while that for $R=18 \mathrm{~km}$ does not. The observed record is intermediate between the two cases. The reverberation is due to the resonance of the near-station structure, such as a bay or harbor. If the source dimension is

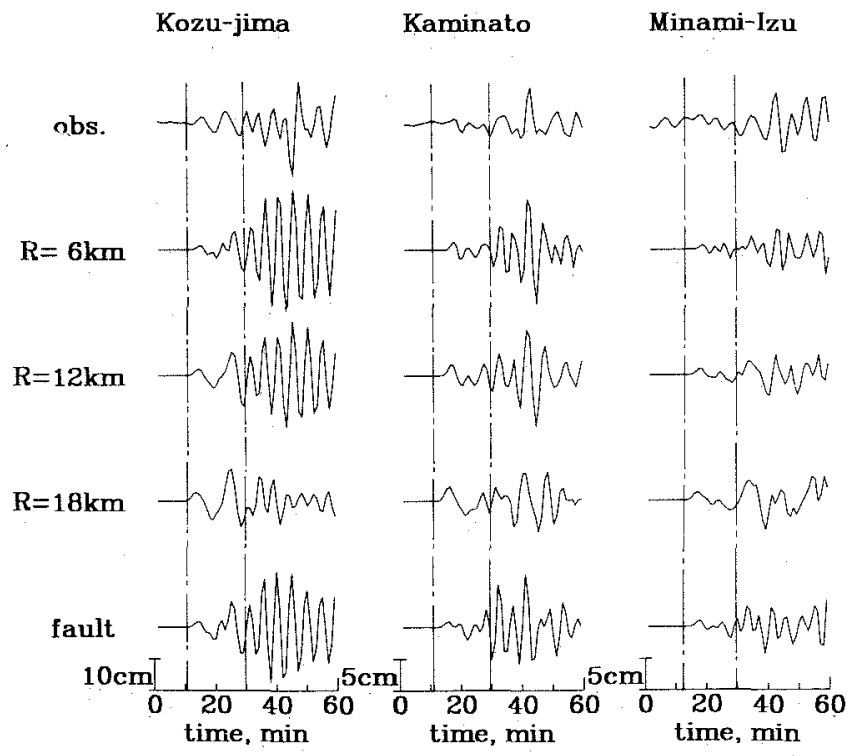

Fig. 4. Comparison of the observed and computed tsunami waveforms at three stations from different source models. The top traces are the observed waveforms, the middle three are for circular sources with different radii, and the bottom one is from a fault model expected from an $M_{w}=6.3$ event. small, the resulting tsunami has a relatively large amount of short-period energy which gives rise to resonance with the near-station structure. If the source dimension becomes large, the dominant frequency of the source spectrum moves out of the resonance range. From this observation, $R$ is estimated to be $12 \mathrm{~km}$ or slightly larger. For Kaminato (Hachijo-jima) and Minami-Izu (Figure 4) the overall character of the waveforms suggests $R=6$ to $12 \mathrm{~km}$. The discrepancy between the estimates obtained above is probably caused by our incomplete knowledge of the bathymetry. Allowing for all the uncertainties in the modeling, we can conclude that $R=12 \mathrm{~km}$ is a reasonable estimate for the radius of the source area, but, in view of the above uncertainties, we will consider a range of 6 to $18 \mathrm{~km}$ in the following discussion.

For each source radius, we compare the maximum amplitudes of the observed and computed tsunamis to estimate the source height $H$. The computed tsunami amplitudes for the source with $R=12 \mathrm{~km}$ are plotted in Figure 2 as well as the observed amplitudes. The numerical computation roughly reproduces the amplitude distribution pattern, except for one station, $\mathrm{O}$-shima. A more careful examination of the figure shows that the observed amplitudes are smaller at shorter distances but become larger at longer distances. These discrepancies may be due to incomplete knowledge of the bathymetry. Since the computed tsunami amplitude at $\mathrm{O}$-shima is very different from the general pattern, we disregarded this station in estimating the source height. By averaging the amplitude ratios at the other stations, we get $H=13 \mathrm{~cm}$ for the $R=12 \mathrm{~km}$ source. Similarly, we get $H=23 \mathrm{~cm}$ and $11 \mathrm{~cm}$ for the source radii $R=6$ and 18 $\mathrm{km}$, respectively. Figure 5 is the comparison of the observed waveforms with the computed waveforms for the $R=12 \mathrm{~km}$ source.

From the source radius and the maximum height, we can compute the volume of the displaced water, $V$, by

$$
V=\int_{S} h d S
$$

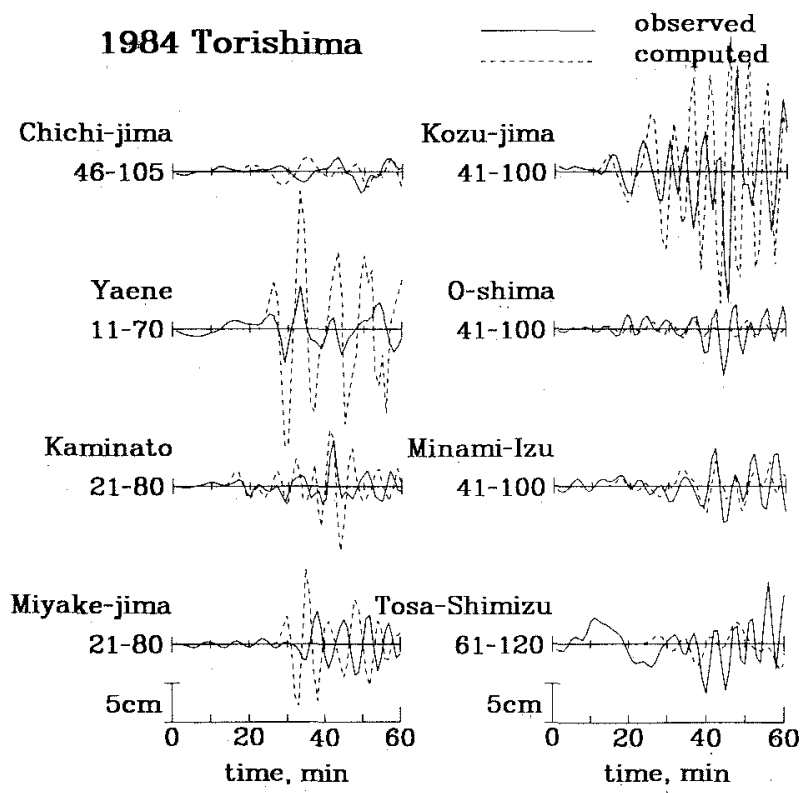

Fig. 5. Comparison of the observed (solid curves) and computed (dashed curves) waveforms from the source model for $R=12 \mathrm{~km}$ and $H=13 \mathrm{~cm}$. The time scale in minutes from the origin time is shown at the bottom. 
where

$$
h=H \sqrt{1-\left(\frac{r}{R}\right)^{2}},
$$

$r$ is the distance from the center and $S$ is the area of the circular source. The potential energy $E_{t}$ of the uplifted water can also be computed by

$$
E_{t}=\frac{1}{2} \rho g \int_{S} h^{2} d S
$$

where $\rho$ is density of water. These quantities are calculated for the three different radii $R$ and plotted in Figure 6. Since the estimated $H$ is roughly inversely proportional to $R$, the source volume $V$ is proportional to $R$, and $E_{t}$ is independent of $R$. This means that the potential energy rather than the source volume determines the tsunami amplitude. From Figure
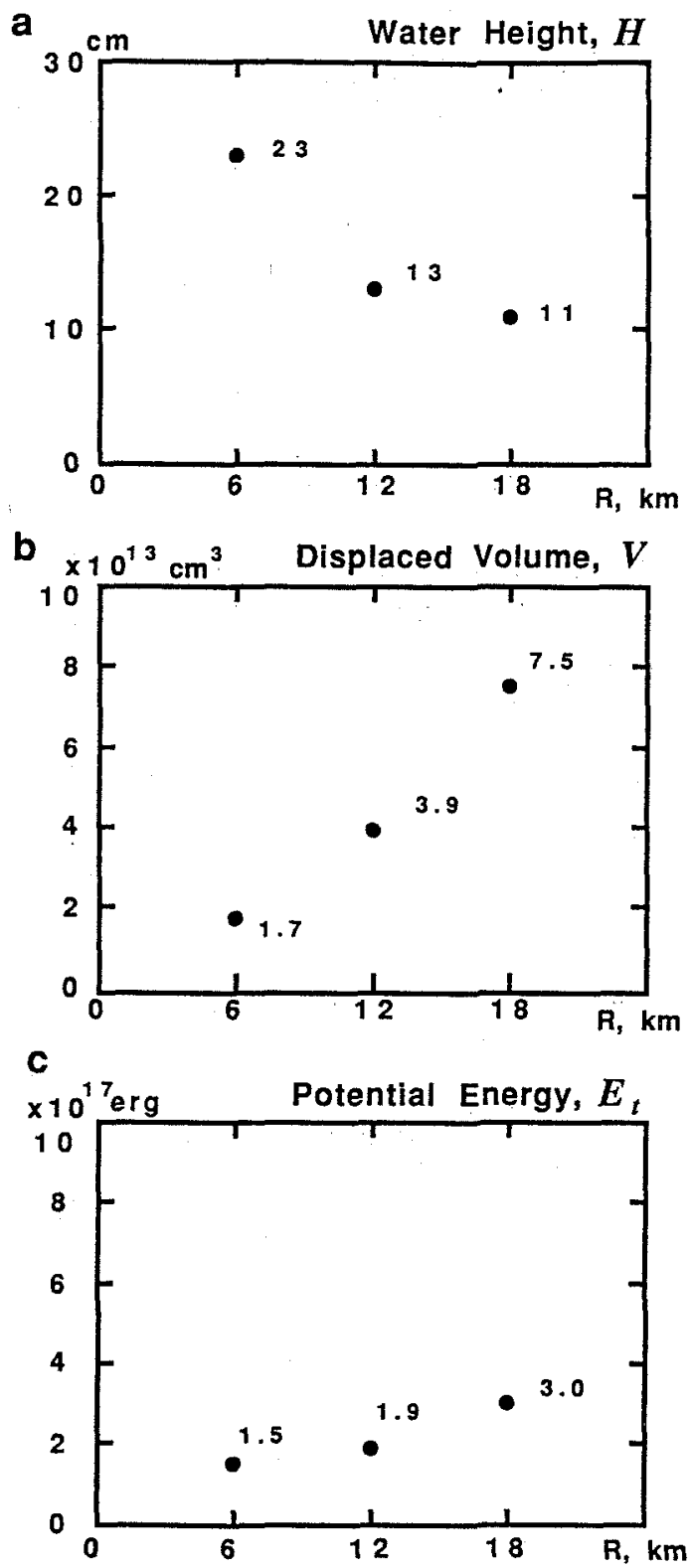

Fig. 6. The source height $H$, the computed source volume $V$, and the potential energy $E_{t}$ for three different radii $R$ estimated from the observations. Note that $H$ is inversely proportional to $R, V$ is proportional to $R$, and $E_{t}$ is roughly constant.
$5 c$, the potential energy is estimated to be $2 \times 10^{17}$ ergs regardless of the source radius.

\section{THE EARTHQUAKe SOURCE MODEL}

We have determined the water surface displacement at the source. If the water depth at the source is much smaller than the wavelength, we can assume that the bottom deformation is the same as the surface displacement. Since the tsunami source of the Torishima event is in very shallow $(300 \mathrm{~m})$ water and the source radius is $12 \mathrm{~km}$, the above assumption is valid. Now we will estimate the earthquake source motion at depth from the ocean bottom deformation. We computed the surface deformation patterns due to shear and tensile faultings using Okada's [1985] program. For simplicity, we assumed that the crustal material is a Poisson solid.

We first assumed that the earthquake source is an ordinary faulting. The geometry of the fault is taken from the centroid moment tensor solution [Dziewonski et al., 1985]. The fault length $24 \mathrm{~km}$, width $12 \mathrm{~km}$, slip $40 \mathrm{~cm}$, dip $45^{\circ}$, strike $55^{\circ}$, rake $90^{\circ}$ and the depth to the fault top $5 \mathrm{~km}$ are assumed. This model yields a maximum uplift of $15 \mathrm{~cm}$, and the potential energy of deformation is $1.6 \times 10^{17} \mathrm{ergs}$; these values are similar to those obtained from tsunami modeling. Moving the fault toward a shallower depth does not change the maximum uplift and the potential energy significantly, because the fault extends to some depth [Kajiura, 1981]. The tsunami waveforms from this model are shown in Figure 4. The computed waveforms and amplitudes are comparable to the observed waveforms, suggesting that the surface deformation from the fault model is comparable in tsunami excitation with the circular uplift if both have the same potential energy. If we assume that the rigidity at the source is $3 \mathrm{x}$ $10^{11} \mathrm{dyn} / \mathrm{cm}^{2}$, the seismic moment from this fault model is 3 x $10^{25}$ dyn $\mathrm{cm}$ which corresponds to $M_{w}=6.3$; this is larger than the observed $M_{w}$ (5.6) by 0.7 unit. This difference in $M_{w}$ corresponds to a difference of a factor of 5 in tsunami amplitude. In other words, the tsunamis generated by the Torishima earthquake are 5 times larger than those expected for an earthquake with $M_{w}=5.6$, the value determined from seismic data.

One way to explain this magnitude discrepancy is to put the source in a very weak material at a shallow depth (probably within low-rigidity sediment). Since the far-field seismic amplitude is proportional to the seismic potency [Ben-Menahem and Singh, 1981], the product of fault slip and the fault area, a seismic source in a low-rigidity medium yields large far-field seismic amplitude and ocean bottom displacement even if its seismic moment is small. This idea has been proposed by Fukao [1979], Ward [1979] and Wiens [1989] to explain the cause of tsunami earthquakes in subduction zones. The moment of the Torishima event from seismic data is about an order of magnitude smaller than that estimated from tsunamis. Thus to explain the Torishima tsunami with a source in a low-rigidity medium, the average rigidity of the material surrounding the entire fault (up to about $10 \mathrm{~km}$ in depth) must be an order of magnitude smaller than the value used in the seismic model; the rigidity must be about $3 \times 10^{10} \mathrm{dyn} / \mathrm{cm}^{2}$. The $P$ wave velocity and density would be $2 \mathrm{~km} / \mathrm{s}$ and $2 \mathrm{~g} / \mathrm{cm}^{3}$, respectively, in such a lowrigidity material. It is unlikely that the top $10 \mathrm{~km}$ of the crust is that soft in the ridge system.

We next examine the tensile fault model suggested by 
Kanamori et al. [1986]. A tensile motion on a horizontally lying fault produces a larger surface displacement than a shear motion on a dipping fault if the potency is the same. We assumed a square fault with a size of $15 \mathrm{~km} \mathrm{x} 15 \mathrm{~km}$ and computed the maximum surface uplift and the potential energy for several combinations of depth and tensile opening. A tensile opening of $18 \mathrm{~cm}$ on a fault at a depth of $5 \mathrm{~km}$ produces a maximum uplift of $16 \mathrm{~cm}$ and a potential energy of $1.8 \times 10^{17} \mathrm{ergs}$, similar to the observations. Since the fault has a finite area, a fault in a shallower depth gives a similar surface displacement. If the CLVD source estimated from seismic observation is a combination of the tensile crack and an implosion, the moment tensor element $M_{z z}$ is

$$
M_{z z}=\frac{4}{3} \mu u \Sigma
$$

where $u$ is tensile displacement, $\mu$ is rigidity at the source and $\Sigma$ is fault area [Kanamori et al.,1986]. We did not consider the surface deformation due to the implosive source, because it is presumably deeper than the tensile crack. Substituting the above estimates and assuming that $\mu=3 \times 10^{11} \mathrm{dyn} / \mathrm{cm}^{2}$, we obtain $M_{z z}=1.8 \times 10^{25} \mathrm{dyn} \mathrm{cm}$, which is about a factor of 5 larger than the seismic obser-
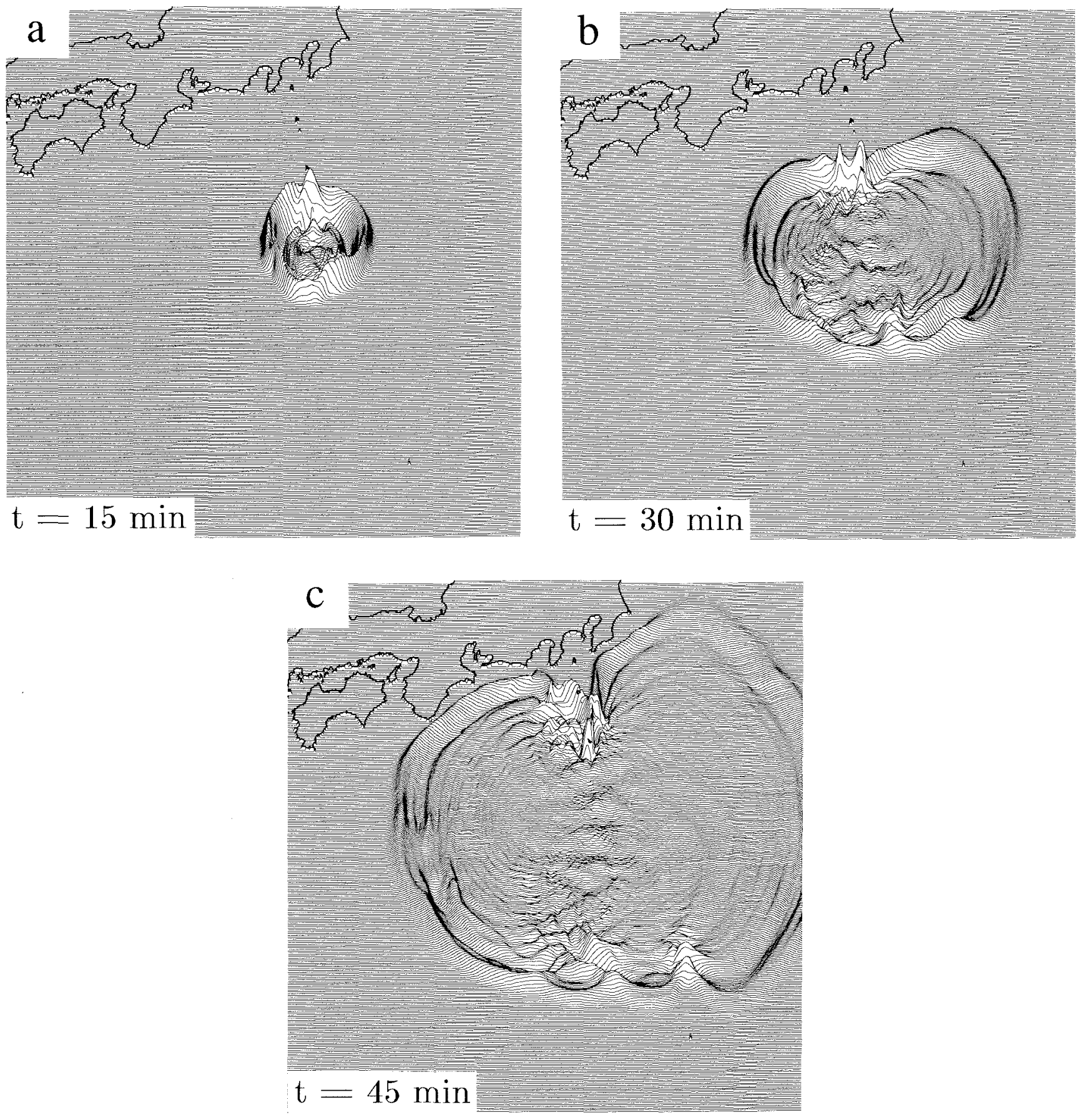

Fig. 7. Water height distribution computed by a finite difference method (a) $15 \mathrm{~min},(b) 30 \mathrm{~min}$, and (c) 45 min after the origin time. Note that the amplitude is large in the north-south direction from the source where the water depth is shallow (see Figure 1). 
vation, $4 \times 10^{24} \mathrm{dyn} \mathrm{cm}$. This discrepancy can be reconciled by making the rigidity smaller, i.e., $7 \times 10^{10} \mathrm{dyn} / \mathrm{cm}^{2}$, or moving the fault into a shallower depth. If the depth is 2 $\mathrm{km}$, a crack opening of $15 \mathrm{~cm}$ produces a maximum uplift of $15 \mathrm{~cm}$ and a potential energy of $1.9 \times 10^{17}$ ergs In this case, the rigidity of $9 \times 10^{10} \mathrm{dyn} / \mathrm{cm}^{2}$ will explain the seismologically observed $M_{z z}$ and the tsunami observation. This rigidity corresponds to the $P$ wave velocity of $3.3 \mathrm{~km} / \mathrm{s}$ and density $\rho=2.5 \mathrm{~g} / \mathrm{cm}^{3}$. This is a reasonable value for the average over the top $2 \mathrm{~km}$ of the crust.

In summary, to explain the surface displacement estimated from tsunamis, an ordinary fault model requires a larger seismic moment than observed. The tensile fault model suggested by Kanamori et al. [1986] for a shallow depth can explain both the tsunami and seismic observations.

\section{ABNormal Tsunami Propagation}

The difference between the tsunami magnitude $M_{t}=7.3$ estimated by $A b e$ [1988] and $M_{w}=6.3$ inferred from the numerical calculations using a fault model is most likely due to the path effect. The tsunami magnitude formula [Abe, 1981, 1988] implies that the amplitudes decay with distance in the same way as for a uniform-depth ocean. In our study the actual bathymetry is used to account for the path effect. The Torishima earthquake is located on a shallow ridge system which is parallel to the Japan Trench. The water depth along the ridge is about $1000 \mathrm{~m}$ (Figure 1). The islands where the large tsunamis were observed are also located on this ridge. This particular geometry caused tsunami energy to focus on the Japanese islands. This effect is most clearly seen in the snapshots of the wave field shown in Figure 7, which show the wave height distribution at 15,30 and $45 \mathrm{~min}$ after the origin time. Up to $15 \mathrm{~min}$, the tsunami propagates at an almost uniform velocity and the amplitude is almost uniform, although a small peak can be seen in the north direction. At $30 \mathrm{~min}$, propagation has progressed further in the northeast direction than in the other directions, because of the deep Japan Trench, where the tsunami velocity is high. The amplitude is very large in the north direction. Similar features are also seen at $45 \mathrm{~min}$. Because the velocity is slow in the north and south directions, focusing of energy occurred in these directions. The abnormally large tsunamis were observed in these directions, which resulted in the large tsunami magnitude $M_{t}$.

\section{CONCLUSIONS}

We have modeled the tsunami source of the Torishima earthquake as a circular source area with radius $12 \mathrm{~km}$ and an elliptic water uplift with maximum amplitude of $13 \mathrm{~cm}$. The volume of the uplifted water is $4 \times 10^{13} \mathrm{~cm}^{3}$ and the potential energy is $2 \times 10^{17}$ ergs.

We found that the amplitude of tsunamis is primarily determined by the potential energy change at the source. If we assume that the earthquake source is an ordinary faulting, the moment magnitude $M_{w}$ is expected to be 6.3 for a depth of $5 \mathrm{~km}$. This value is larger than $M_{w}$ estimated from seismic waves by 0.7 , but smaller than $M_{t}$ by 1.0 . The former discrepancy is due to an abnormal source property, while the latter is due to the abnormal tsunami propagation along a shallow ridge system. As an abnormal earthquake source, a tensile fault at shallow depth as suggested by
Kanamori et al. [1986] explains both the tsunami source and the seismic moment tensor. Thus both the source and path effects caused the abnormally large tsunamis.

Acknowledgments. We used the bathymetry dataset JTOPO1 compiled by $M$. Okada, Meteorological Research Institute, Japan. This work was supported by USGS grant 14-08-001 G1356 and NSF grant EAR 89-15987. K.S. is also supported by a Fellowship for Research Abroad from the Japan Society for the Promotion of Science. Contribution 4768, Division of Geological and Planetary Sciences, California Institute of Technology.

\section{REFERENCES}

Abe, K., Size of great earthquakes of 1837-1974 inferred from tsunami data, J. Geophys. Res., 84, 1561-1568, 1979.

Abe, K., Physical size of tsunamigenic earthquakes of the northwestern Pacific, Phys. Earth Planet. Inter., 27, 194 205,1981 .

Abe, K., Tsunami magnitude and the quantification of earthquake tsunamis around Japan, Bull. Earthquake Res. Inst. Univ. Tokyo, 63, 289-303, 1988.

Aida, I., Reliability of a tsunami source model derived from fault parameters, J. Phys. Earth, 26, 57-73, 1978.

Ando, M., A fault model of the 1946 Nankaido earthquake derived from tsunami data, Phys. Earth Planet. Inter., 28, 320-336, 1982.

Ben-Menahem, A. and S.J. Singh, Seismic Waves and Sources, p.179, Springer-Verlag, 1981.

Comer, R.P., Tsunami height and earthquake magnitude: Theoretical basis of an empirical relation, Geophys. Res. Lett., 7, 445-448, 1980.

Comer, R.P., The tsunami mode of a flat earth and its excitation by earthquake sources, Geophys. J. R. astr. Soc., 77, 1-27, 1984.

Dziewonski, A.M., J.E. Franzen, and J.H. Woodhouse, Centroid-moment tensor solutions for April-June, 1984, Phys. Earth Planet. Inter., 37, 87-96, 1985.

Fukao, Y., Tsunami earthquakes and subduction processes near deep-sea trenches, J. Geophys. Res., 84, 2303-2314, 1979.

Hatori, T., Irregular tsunami generated by the TorishimaKinkai earthquake (Izu-Mariana region) on June 13, 1984 Bull. Earthquake Res. Inst. Univ. Tokyo, 60, 87-95, 1985. Kajiura, K., The leading wave of a tsunami, Bull. Earthquake Res. Inst. Univ. Tokyo, 41, 535-571, 1963.

Kajiura, K., Tsunami energy in relation to parameters of the earthquake fault model, Bull. Earthquake Res. Inst. Univ. Tokyo, 56, 415-440, 1981.

Kanamori, H., Mechanism of tsunami earthquakes, Phys. Earth Planet. Inter., 6, 346-359, 1972.

Kanamori, H., G. Ekström, A. Dziewonski, and J.S. Barker, An anomalous seismic event near Tori Shima, Japan - A possible magma injection event (abstract), Eos Trans. $A G U, 67,1117,1986$.

Okada, M., Tsunamis generated by the June 13, 1984 earthquake near Torishima (abstract), Program Abstr. Seismol. Soc. Jpn., No.2, 166, 1984.

Okada, Y., Surface deformation due to shear and tensile faults in a half-space, Bull. Seismol. Soc. Am., 75, 1135-1154, 1985.

Okal, E.A., Seismic parameters controlling far-field tsunami amplitudes: A review, Natural Hazards, 1, 67-96, 1988.

Satake, K., Inversion of tsunami waveforms for the estimation of heterogeneous fault motion of large submarine earthquakes: The 1968 Tokachi-oki and 1983 Japan Sea earthquakes, J. Geophys. Res., 94, 5627-5636, 1989.

Takahashi, R., On seismic sea waves caused by deformations of the sea bottom, Bull. Earthquake Res. Inst. Univ. Tokyo, 20, 375-400, 1942.

Ward, S. N., Ringing $\mathrm{P}$ waves and submarine faulting, $J$. Geophys. Res., 84, 3057-3062, 1979. 
Ward, S. N., Relationships of tsunami generation and an earthquake source, J. Phys. Earth, 28, 441-474, 1980.

Wiens, D.A., Bathymetric effects on body waveforms from shallow subduction zone earthquakes and application to seismic processes in the Kuril trench, J. Geophys. Res., 94, 2955-2972, 1989.

H. Kanamori, Seismological Laboratory, 252-21, California Institute of Technology, Pasadena, CA 91125.
K. Satake, Department of Geological Sciences, University of Michigan, 1006 C. C. Little Building, Ann Arbor, MI 48109.

(Received June 5, 1989; revised March 4, 1991; accepted June 19, 1991.) 